Universidad Nacional de La Plata.

Facultad de Humanidades y Ciencias de la Educación.

Centro de Investigaciones Socio Históricas

\title{
Rieles y política económica durante la última dictadura cívico-militar argentina (1976-1983)
}

\author{
Rails and economic policy during the last Argentinian civil-military \\ dictatorship (1976-1983)
}

\section{Lucas Iramain*; Verónica Pérez*}

* Instituto de Altos Estudios Sociales - Universidad Nacional de San Martín (IDAESUNSAM), Argentina | lucasiramain@yahoo.com; veronikaperez@gmail.com

\section{PALABRAS CLAVE}

Ferrocarriles

Dictadura

Política económica

\section{KEYWORDS}

Railroads

Dictatorship

Economic policy

\section{RESUMEN}

Este artículo aborda el impacto que la política económica implementada por la última dictadura cívicomilitar argentina (1976-1983) surtió sobre el desempeño de la empresa Ferrocarriles Argentinos. El objetivo central del trabajo es analizar la política desplegada en el sector ferroviario, en diálogo con el proceso general de intervención económica estatal que tuvo lugar durante la gestión de Martínez de Hoz al frente del Ministerio de Economía. La hipótesis propuesta es que dicha política fue funcional a los propósitos refundacionales de la última dictadura, esencialmente, en lo atinente al rol del Estado en materia de intervención económica y a la revancha clasista que se emprendió en contra de los sectores populares. Para los argumentos desarrollados se analizaron articuladamente estudios específicos sobre la temática con datos estadísticos de la Sindicatura General de Empresas Públicas y de los reportes estadísticos de la firma Ferrocarriles Argentinos, entre otros.

\section{ABSTRACT}

This article addresses the impact of the economic policy implemented by the last civil-military dictatorship in Argentina (1976-1983) on the company Ferrocarriles Argentinos. The main objective is to analyze the policy deployed in the railway sector, in dialogue with the general process of state economic intervention during the administration of Martinez de Hoz at the Ministry of Economy. The proposed hypothesis is that such a policy was functional to the re-foundational purposes of the last dictatorship, essentially in relation to the role of the State in the field of economic intervention and to the classist retaliation undertook against the popular sectors. In order to develop our arguments we articulate the analysis of specific studies on the subject with statistical data from the General Court of Public Enterprises and statistical reports of the Ferrocarriles Argentinos company, among others. 


\section{Introducción}

La última dictadura cívico-militar argentina (1976-1983) implicó, entre otras cuestiones, una profunda revancha clasista que tuvo como pilares centrales al terrorismo de Estado y a la política económica implementada por Martínez de Hoz. Sus efectos sobre la sociedad y la economía argentinas, que habrían de dejar huellas perdurables, conllevaron un feroz disciplinamiento de los sectores populares en general y de la clase trabajadora en particular. Dicho disciplinamiento, tal como lo ha demostrado la literatura especializada, se sintió con inusitado rigor en el sector industrial, como producto de la deliberada estrategia de agresión y redimensionamiento del tejido manufacturero que desplegó la gestión liberal-corporativa de Martínez de Hoz al frente del Ministerio de Economía de la Nación (1976-1981). ${ }^{1}$ La misma fue implementada con el propósito de revertir décadas enteras en las cuales la industria local se había constituido en el eje ordenador, articulador y dinamizador de las relaciones económicas, políticas y sociales en la Argentina y, de ese modo, quebrar la bases sociales de sustentación que habían permitido experiencias políticas como la del peronismo.

Sin embargo, se ha explorado de manera relativamente escasa el impacto que la política económica surtió sobre el desempeño de las empresas y organismos públicos y, en especial, las consecuencias que tuvo sobre los ferrocarriles. En efecto, estos últimos no estuvieron exentos de la estrategia de achicamiento del aparato estatal que se plasmó de manera paradigmática en el llamado "principio de subsidiariedad del Estado" y la denominada política de "privatización periférica” de empresas estatales.

Cabe recordar que la reducción del tamaño del Estado y la disminución de su injerencia en la vida económica fueron dos de los objetivos principales de la gestión "eficientista” y "modernizadora" de Martínez de Hoz. Esta política fue desplegada en el marco de un contexto internacional de crítica y reversión de las ideas keynesianas y de ataque global al modelo de funcionamiento del capitalismo de posguerra, que dentro del concepto amplio de Estado de Bienestar incluía al Estado empresario ${ }^{2}$ (Regalsky y Rougier, 2015:12). En sintonía con esta orientación ideológica, la política implementada por Martínez de Hoz tuvo como uno de sus capítulos más importantes la enajenación de activos estatales y la aplicación de una intensa política de racionalización de los planteles laborales de las firmas y reparticiones públicas.

Sin embargo, el proceso antedicho no fue lineal. Si por un lado la tentativa de reducir la presencia estatal en la economía doméstica supuso, entre otras cosas, una fuerte intervención gubernamental en las relaciones económicas y laborales, al punto de terciar de manera ostensible en la relación capital-trabajo asalariado, con un sesgo favorable al primero de ellos, por otro, si bien se reducía personal en las empresas y agencias estatales, el Estado asumía cada vez más actividades, producto del crecimiento del llamado “complejo económico estatal -privado" y la concomitante configuración de diversos "ámbitos privilegiados de acumulación de capital” (Castellani, 2009). Esto conllevaría, tal como lo ha señalado Schvarzer (1986), a la expansión económica del "Estado subsidiario". Asimismo, durante este período se mantuvieron los mecanismos de promoción industrial para grandes compañías y se incorporaron a la órbita estatal nuevas empresas.

En el caso particular de los ferrocarriles, el autodenominado Proceso de Reorganización Nacional, recuperó muchas de las propuestas de desarticulación y desmantelamiento de la red ferroviaria que durante la gestión de gobierno de Arturo Frondizi (1958-1962) habían sido plasmadas en el conocido Plan Larkin. Pero esta vez, las mismas serían implementadas en el marco de un proyecto político - económico refundacional del capitalismo argentino. En ese contexto, la gestión procesista en materia de transporte ferroviario constituyó un capítulo más de la estrategia política y económico-social desplegada por la última dictadura, dado que asestaría un severo golpe al modo de desarrollo económico y social que se había instaurado en la Argentina a partir de la crisis de 1930.

Así como se produjo una verdadera agresión al tejido manufacturero local, dando inicio a varias décadas de acentuada desindustrialización de la economía argentina, también se verificó durante el período 1976-1983, 
una decidida embestida contra el sistema ferroviario, el cual era sindicado como económicamente poco rentable, ineficiente y deficitario.

En ese sentido, el presente trabajo constituye una aproximación a los impactos que la política económica de la dictadura tuvo sobre la empresa estatal Ferrocarriles Argentinos (FA). El objetivo central es analizar, dentro del programa económico del Proceso, en especial durante la gestión de Martínez de Hoz al frente del Ministerio de Economía de la Nación (1976-1981), la política de transporte desplegada en el estratégico sector ferroviario, en aras de aportar, a través de un estudio de caso, evidencia empírica que avale la hipótesis que postula la funcionalidad de dicha política en relación a los propósitos refundacionales de la última dictadura cívico-militar, en particular, su determinación de reducir la presencia del Estado en la economía y su adecuación a la revancha clasista que se emprendió en contra de los sectores populares.

Para tales fines, este artículo se divide en total, en cuatro apartados. En el primero, se analiza el proceso de desmantelamiento de la red ferroviaria, en el marco del más vasto proyecto de redimensionamiento del Estado empresario en la economía argentina. En el segundo y tercero, se aborda la performance económicofinanciera de FA en función de las principales variables de desempeño; tales como nivel de actividad, ingresos, gastos, tarifas, evolución del endeudamiento interno y externo, niveles de inversión etc. En el cuarto se examina, a partir de una serie de indicadores tales como evolución de la dotación de personal, salarios, productividad, y niveles de ausentismo, la política de racionalización aplicada en materia laboral, como parte integrante de la estrategia gubernamental más amplia de disciplinamiento de los sectores populares en general y de los trabajadores ferroviarios en particular. Finalmente, se esbozan las conclusiones del trabajo.

\section{La desarticulación del Estado empresario en el ámbito ferroviario}

El ejemplo más difícil... el de los ferrocarriles, que todavía reciben un aporte sustancial del tesoro para poder sobrevivir. Allí también hemos realizado una muy importante obra de racionalización y de reorganización (...) Esta acción en todos sus aspectos, (...) ha sido muy dura. Ha sido muy difícil hacer comprender a estructuras administrativas verdaderamente enquistadas la importancia de la reducción de costos y de la operación con eficiencia. Creo que hemos logrado mucho, pero quizás estemos a mitad de camino de lo necesario y esta acción debe ser perseguida con mucha firmeza. Cualquier aflojamiento o cualquier falta de apoyo o de firmeza, o cualquier retroceso en este sentido, puede hacer perder todo el esfuerzo que se ha ganado y los resultados que se han ganado en estos pasados años.

Extracto del discurso del Ministro de Economía, José Alfredo Martínez de Hoz (12/03/1981)

Los señalamientos del entonces Ministro de Economía respecto a la política ferroviaria implementada a partir de 1976, describen los lineamientos principales que rigieron las acciones en la materia. Conceptos como los de racionalización, reducción de costos y eficiencia, sin ser privativos del ámbito ferroviario, funcionaron como el sustrato ideológico de las reformas que inaugurarían un nuevo ciclo económico en Argentina. Sin embargo, cabe resaltar que como sucede con todo concepto, el significado de los mismos se hizo inteligible en el marco de un nuevo paradigma, contenedor del desenvolvimiento de un nuevo patrón de acumulación. Así, la apelación a la necesaria racionalización del servicio, operó un desplazamiento hacia criterios de mercantilización que, como se verá más adelante, se llevó a cabo principalmente a partir de la apertura de posibilidades de negocios a un conjunto de grupos económicos que se beneficiaron con la política de privatización periférica. De esta manera, racionalidad económica y racionalidad mercantil se 
solaparon bajo una misma significación. Otro tanto sucedió con la reclamación de reducir los costos de las empresas. En el marco de un paradigma que desplazaba la producción de bienes industriales como eje del proceso económico y comenzaba a centrarse en la valorización financiera como eje del modelo de acumulación, el salario perdió el atributo de ser un factor indispensable para asegurar el nivel de demanda y la realización del excedente y comenzó a contar como un costo más (Basualdo, 2010: 117). Esta tendencia se vería fuertemente reflejada en la brusca reducción ya no de los salarios, sino directamente de la planta de trabajadores afectados a la empresa.

Hacia 1976, la conducción del área de transporte quedó radicada en el Ministerio de Economía a través de la Secretaría de Transporte y Obras Públicas (SETOP). Bajo esta órbita, la SETOP elaboró un plan de acción para los ferrocarriles que implicaba reiterar las medidas de racionalización recomendadas 15 años antes por el denominado Plan Larkin. Entre las principales disposiciones el "viejo nuevo" plan, incluía el cierre de ramales antieconómicos, la supresión de trenes de pasajeros de baja utilización, el cierre de talleres redundantes y la supresión de la tracción a vapor (Martínez, 2007:212). Como se desprende del discurso de Martínez de Hoz, los principales objetivos de la política hacia los ferrocarriles fueron alcanzados con éxito.

En efecto, en 1974 la red contaba con una longitud de 39.782 kilómetros de líneas, mientras que al finalizar la dictadura la merma había sido del orden del $14 \%$. De modo análogo, la cantidad de pasajeros transportados también experimentó una sensible caída a lo largo del período bajo análisis. De un nivel de 422.800 pasajeros transportados en 1974, se llegó para el año 1983 a una cifra de 290.000 pasajeros, lo cual representa un decremento entre puntas superior al 30\%. En consonancia con la reducción de la longitud de líneas de la red ferroviaria, también se constató una sustancial reducción en la cantidad de estaciones, que pasaron de un total de 2.391 en 1974 a otro de 1.800 en 1983; es decir, una caída cercana al 25\% entre ambos años. De manera similar, se operó un fuerte descenso en el parque de material rodante (locomotoras y vagones). El número de locomotoras pasó de un total de 2.498 unidades a una cantidad de 1.038 unidades entre los años 1973 y 1983; lo cual, representa, una merma del 58\% entre puntas. En cuanto al parque de vagones, también se verificó un descenso entre los mismos años del orden del 58\% (pasó de un total de 54.602 unidades a una cifra de 36.795 unidades).

El desmantelamiento de los ferrocarriles formó parte de un programa más vasto de desarticulación del Estado empresario y en esa dirección, de privatización de empresas públicas. Como señala Rougier, en el cumplimiento de esta meta destaca la vertiginosidad del proceso. Hacia fines de 1980, 120 empresas en poder del sector público habían sido privatizadas, disueltas, liquidadas, entregadas en comodato, concesionadas o transferidas a la justicia y 46 estaban en proceso aún de privatización. También se había vendido la participación accionaria de 207 empresas y otras 46 se habían dado de baja por quiebra (2008:20). Sin embargo y no obstante su celeridad, el proceso no fue lineal.

Existe una importante literatura (Canelo, 2004; Canelo, 2008; Novaro y Palermo, 2003; Quiroga, 2004; Schvarzer, 1986) que ha señalado los severos obstáculos que enfrentó la política privatizadora de Martínez de Hoz, debido a las reticencias de ciertos sectores de las Fuerzas Armadas que, ya sea, por convicción y adhesión ideológica a un ideario nacionalista, neodesarrollista e industrialista, o por pragmatismo e intereses económicos particulares espurios, se opusieron de manera deliberada a cualquier tentativa de transferir plenamente las empresas estatales al sector privado. En ese marco, la "solución de compromiso" consistió en la llamada política de privatización periférica que creó las condiciones de posibilidad para la consolidación y reforzamiento de las posiciones de ciertas empresas privadas contratistas, como así también para la constitución de nuevos grupos económicos locales beneficiarios de los "nichos de negocios" abiertos por dicha política.

En el caso de la empresa Ferrocarriles Argentinos, el cierre de talleres ferroviarios -resultante directa del redimensionamiento de la empresa - tuvo un lugar destacado en esta dirección, al tiempo que aportó al 
cumplimiento de algunos de los objetivos principales del proceso. En tal sentido una misma medida permitió la consecución de al menos dos metas. Por un lado, fue parte de la política de represión interna que incluyó la desaparición de delegados, coadyuvando a romper la concentración de operarios y eliminando focos de conflictividad (Zlotnik y Dellatorre, 2000), aportando al disciplinamiento de la clase trabajadora. Por otro, por sus efectos sobre la cantidad de personal ocupado, se convirtió en una variable central con vistas a llevar adelante el llamado proceso de racionalización permitiendo a su vez la apertura de nuevas posibilidades de negocios a distintos grupos empresarios, como se verá en el apartado siguiente.

La clausura de talleres ferroviarios fue una política implementada no sin generar conflictos. Su anuncio desató una confrontación entre Ferrocarriles Argentinos (FA) y la SETOP, en torno al momento de su consecución. FA había planteado un plan de mediano plazo que proponía el cierre de establecimientos recién a partir de 1982. Ante la propuesta, la SETOP dispuso el cierre inmediato de tres talleres dedicados a locomotoras de vapor, cuya eliminación estaba en curso: Strobel, Santa Fe y Cruz del Eje. La supresión de la tracción a vapor daría lugar también al cierre de decenas de depósitos en todo el país. Más tarde, la misma disposición se aplicó al taller Tafí Viejo, emblema de los años de oro del ferrocarril en Argentina. Si bien parte del personal calificado afectado por el cierre de los talleres fue reubicado en otros como los de Paraná, Laguna Paiva y Córdoba, la medida afectó severamente la planta de trabajadores de FA (Martínez, 2007:215).

\section{Las resultantes de la racionalización: Los efectos de la política ferroviaria en el nivel de actividad económica de la empresa Ferrocarriles Argentinos.}

Este brutal redimensionamiento de la red ferroviaria tuvo un fuerte impacto en el nivel de actividad de FA. Un primer dato que aporta en esta dirección es la evolución desfavorable de la actividad de la empresa, medida en a partir del producto bruto interno a costo de factores (PBI), el cual en 1981 fue un 26\% más bajo que el del 1974, pasando de 960,2 a 711,2 millones pesos ${ }^{3}$ (SIGEP, 1984), en dicho lapso. En consonancia con esa situación de declinación económica, los ingresos por ventas de la empresa evidenciaron una notable merma, representando entre 1976 y 1983, entre el 60 y el 70\% de los ingresos que por igual concepto, tuvo la empresa en 1965 (SIGEP, 1984). Este proceso de declive de la empresa ferrocarrilera, se tradujo en una importante caída dentro del ranking, confeccionado por la revista Prensa Económica, de las 200 mayores firmas públicas y privadas de la economía argentina bajo el lapso 1975-1983. En esa línea, es dable verificar que en 1976 ocupaba la novena posición en el mencionado ranking, mientras que en 1983 se ubicaba en el número 28 del escalafón.

Otro dato significativo que ilustra el deterioro de dicha firma, se desprende de la comparación entre la evolución de los ingresos totales con el derrotero seguido por los gastos totales y el cálculo del correspondiente coeficiente de explotación del servicio ferroviario. Como se puede observar en la Tabla 1, ingresos y gastos disminuyeron considerablemente y aunque los primeros lo hicieron en mayor magnitud, durante los primeros años la relación entre ambos mejoró relativamente el coeficiente de explotación de la empresa. En particular, entre los años 1977 y 1979, mejora la performance de este indicador, aunque la misma vuelve a agravarse en el trienio subsiguiente. 
Tabla 1. Evolución de ingresos y gastos reales por explotación de FA, 1974-1983 (en millones de \$). Precios base 1970=100, y coeficiente de explotación.

\begin{tabular}{|c|c|c|c|}
\hline Año & $\begin{array}{c}\text { Total } \\
\text { Inaresos }\end{array}$ & $\begin{array}{c}\text { Total } \\
\text { qastos }\end{array}$ & $\begin{array}{c}\text { Coefiente de } \\
\text { explotación }\end{array}$ \\
\hline 1974 & 766,18 & $1.441,40$ & 1,88 \\
\hline 1975 & 610,80 & $1.651,72$ & 2,70 \\
\hline 1976 & 639,45 & $1.286,84$ & 2,01 \\
\hline 1977 & 600,32 & $1.069,38$ & 1,78 \\
\hline 1978 & 597,29 & $1.007,42$ & 1,69 \\
\hline 1979 & 547,98 & $1.061,40$ & 1,94 \\
\hline 1980 & 532,17 & $1.139,80$ & 2,44 \\
\hline 1981 & 459,75 & 971,74 & 2,11 \\
\hline 1982 & 375,63 & 800,71 & 2,13 \\
\hline 1983 & 602,31 & $1.105,89$ & 1,84 \\
\hline $\begin{array}{c}\text { Variación } \\
\text { porcentual } \\
\text { (74-83) }\end{array}$ & $-21,4$ & $-23,3$ & \\
\hline
\end{tabular}

Fuente: Elaboración propia con base a datos Ferrocarriles Argentinos (1975-1990).

Cabe resaltar que el problema de los abultados déficit de FA venía de larga data, en particular se había agravado durante el gobierno de Frondizi (1958-1962). Sin embargo, los programas de racionalización implementados, primero en 1961 y luego a partir de 1976, no fueron exitosos en términos de reducción del déficit fiscal. Como señala Müller (2012:17), la reducción del emprendimiento ferroviario no parece haber sido el camino correcto en esta dirección, pese a las mínimas mejoras temporales.

Ahora bien, para mejor comprensión del carácter de la política que implementó la empresa durante la etapa bajo análisis, el estudio de la evolución de los diferentes componentes del gasto ${ }^{4}$ permite visualizar con suficiente nitidez, no sólo cuál fue la principal variable de ajuste sino, la considerable transferencia de ingresos que se operó desde la compañía estatal hacia el capital privado. En consonancia con los argumentos desarrollados en el apartado anterior, la evidencia empírica disponible que se presenta seguidamente resulta elocuente.

Un primer dato a tener en cuenta es que no todos los componentes del gasto tuvieron igual comportamiento durante los años bajo estudio. Como se observa en la Figura 1, el gasto que más redujo su peso sobre el total fue el rubro gastos en personal, que lo hizo en un 34\% entre los años 1974 y 1983. Esta fue sin duda la principal variable de ajuste de la empresa. Otra lectura que arroja resultados en la misma dirección es que mientras en 1975 los gastos en personal representaban el 85\% de los gastos por explotación, en 1983 apenas explicaban el 66\%. Por su parte, los gastos en materiales y combustibles se redujeron en un $28 \%$ y $19 \%$ respectivamente, producto lógico de la menor actividad de la empresa estatal. Sin embargo, la evolución que mostraron los egresos derivados de los pagos a contratistas, muestra un comportamiento no sólo cabalmente opuesto a las tendencias decrecientes del resto de los gastos, sino de una intensidad que no se observa en otras variables. Los mismos aumentaron un 348\% en igual período, lo que muestra a las claras quiénes fueron los principales beneficiarios del llamado proceso de racionalización, tal como se argumentó en el apartado anterior. 
Figura 1. Evolución de los principales componentes de los gastos reales por explotación de Ferrocarriles Argentinos, 1974-1983 (en millones de pesos) Precios base 1970=100.

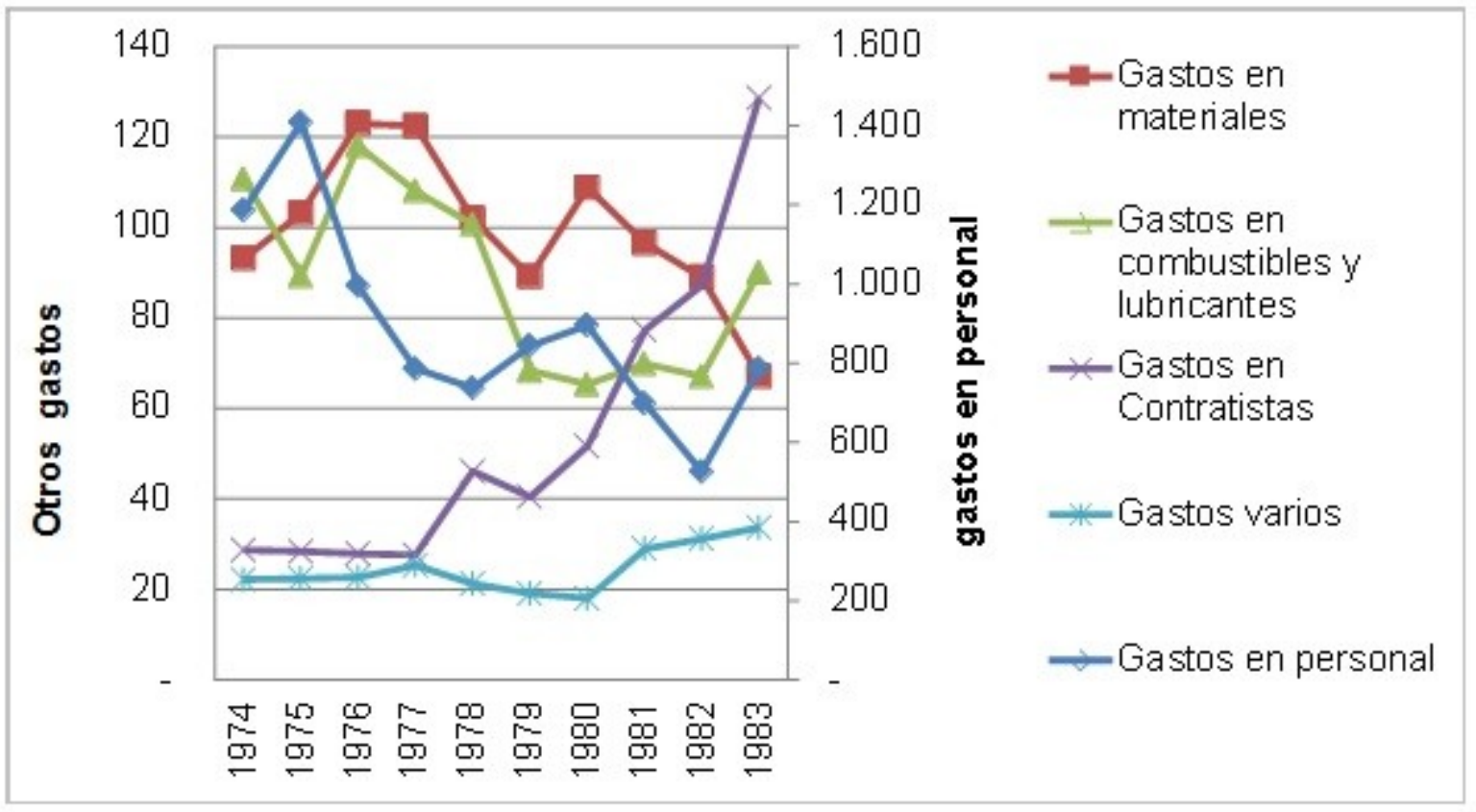

Fuente: Elaboración propia con base a Ferrocarriles Argentinos, 1975-1985

Como se ha señalado en el apartado anterior, el avance en la política de privatización periférica, donde el cierre de talleres ferroviarios constituyó un capítulo central, permitió la transferencia de buena parte de las actividades que realizaba la empresa estatal al sector privado ampliando las posibilidades de negocios para grupos de contratistas beneficiarios de la subcontratación y tercerización de las tareas de mantenimiento y reparación del material ferroviario. Así, entre 1976 y 1982, los gastos en este rubro -gastos en contratistaspasaron de representar el 2,2\% a explicar casi el 11\% de los gastos totales de la empresa (Ferrocarriles Argentinos, 1975-1984).

Los principales beneficiarios de esa política, según afirmaciones efectuadas por Gastiazoro (1988) fueron, en su mayoría, grandes empresas privadas pertenecientes al capital concentrado interno y, más específicamente, a la denominada "patria contratista". Destacan entre ellas las firmas Sade, controlada por el grupo económico local Pérez Companc; Material Ferroviario S.A. (Materfer), donde participaban los grupos locales Intermendoza-Taurales y Boris Garfunkel e Hijos (BGH); Construcciones Metálicas Argentinas S.A. (Cometarsa), controlada por el conglomerado extranjero Techint (Acevedo, Basualdo y Khavisse, 1991) y Astilleros Argentinos Río de la Plata S. A. (Astarsa), cuyos accionistas principales eran los miembros de la familia Braun Menéndez (Dandan, 2011). No obstante, cabe señalar que todavía se requieren más estudios que aporten información fehaciente, susceptible de corroborar la incidencia de esos grupos económicos locales y extranjeros en la privatización periférica de Ferrocarriles Argentinos.

De lo que no caben dudas, es de la intención del propio gabinete económico de concretar esa transferencia de tareas desde dicha firma pública al sector privado. De hecho, sus propósitos fueron expuestos de manera nítida en las memorias que reseñaron el conjunto de la gestión de Martínez de Hoz. Allí se puede leer, sin ambages, cómo el objetivo fundamental era combinar el redimensionamiento y/o cierre de talleres con la recurrencia a la iniciativa privada. Así las cosas, se indicaba que era menester: 
[La] Concentración de establecimientos de atención mecánica y equipos, a efectos de aprovechar los beneficios de la especialización y de la economía de escala, paralelo al programa de reducción de marcas y tipos, recurriendo en la mayor medida a la colaboración de la capacidad industrial privada.

[El] Desplazamiento hacia la iniciativa privada de actividades periféricas, incluso complementación con ella en ciertas y determinadas líneas y prestaciones de transporte (Ministerio de Economía, 1982:243-246).

Ahora bien, pese al brutal incremento de las transferencias a los contratistas del Estado que participaron de los negocios abiertos por la política de racionalización del ferrocarril, el propósito de reducir las erogaciones estatales para sostener una empresa que desde hacía tiempo venía siendo catalogada como ineficiente, se llevó a cabo con éxito. Así, en el marco general de la ofensiva desatada contra el Estado empresario, los aportes el tesoro nacional (ATN) destinados a sostener la actividad ferroviaria, fueron reducidos drásticamente. Hacia 1976 los ATN recibidos por FA habían tocado el pico más alto de la década, alcanzando los 195,7 millones de pesos (de 1960). Luego, entre 1976 y 1978, dichas erogaciones se redujeron en más de 3 cuartos $(77,2 \%)$ y si bien mostraron una paulatina recuperación a partir de 1979, sus valores no alcanzaron los guarismos de 1976 .

Sin embargo, el caso bajo estudio muestra tensiones entre dos objetivos de política económica que caracterizaron los años de la última dictadura: la utilización del control de precios como parte de la política antiinflacionaria y la pretendida necesidad de racionalizar el gasto. Si por un lado la necesidad de reducir el gasto público era asimilada como uno de los factores explicativos por excelencia para comprender el proceso inflacionario, el manejo de los niveles tarifarios como herramienta de política económica implementada en la misma dirección, incidiría negativamente en la consecución del objetivo anterior ${ }^{5}$. Así, como puede observarse en la Figura 2, entre 1976 y 1979, la fluctuación de los niveles tarifarios constituye una variable complementaria -aunque no la única- del monto alcanzado por las erogaciones del tesoro, de tal manera que a menores niveles tarifarios corresponden mayores aportes estatales, confirmándose también la relación inversa.

Figura 2: Relación entre la evolución de los precios de las tarifas de FA y de los Aportes del Tesoro Nacional, a precios constantes. Base 1965=100*. 1974-1983.

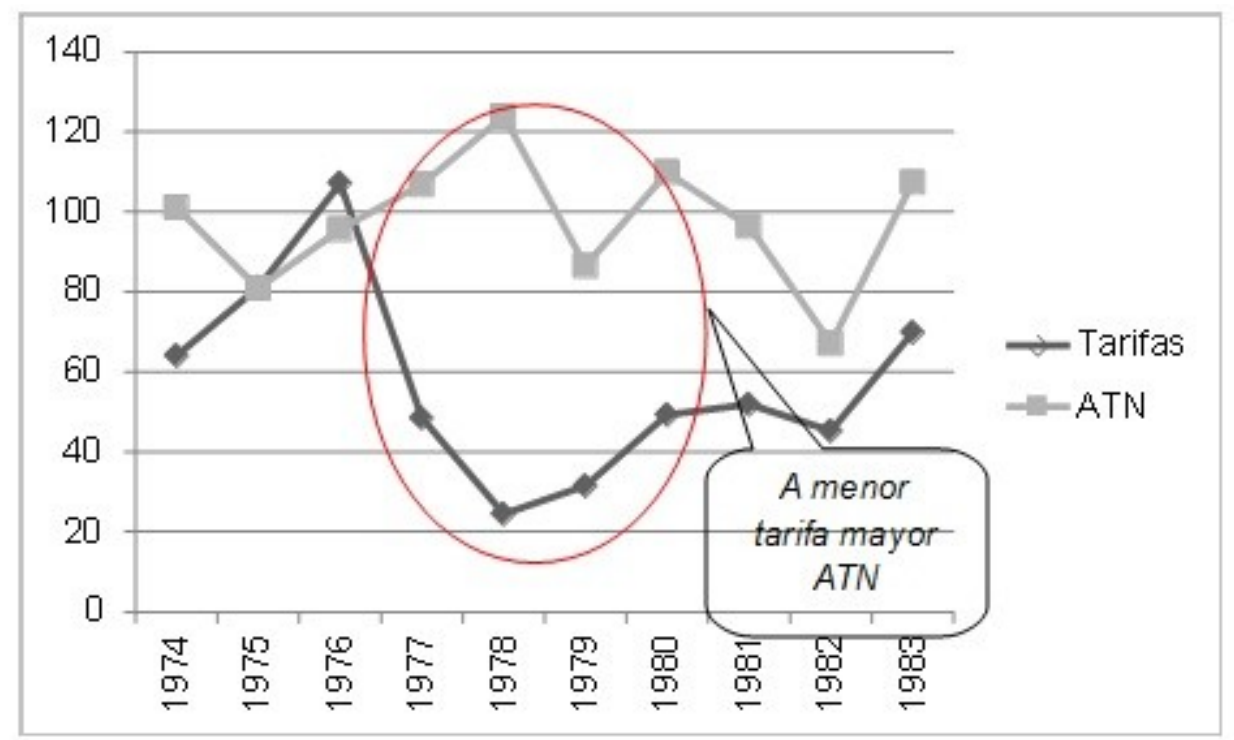

*Deflactado por el Índice de Precios Mayoristas Nacionales no Agropecuarios. Fuente: Elaboración propia con base a datos de la SIGEP (1984) 
Post 1979, la relación citada en el párrafo precedente no se verifica, lo que muestra la incidencia de otros factores. Los ATN vuelven a incrementarse y los niveles tarifarios oscilan, aunque con una tendencia a la alza que, sin embargo, no alcanza a revertir el deterioro de dicha variable, cuyo valor representaba hacia 1982, apenas el 66.2\% de los valores alcanzados en 1960.

\section{Endeudamiento e inversión: Los pilares del nuevo patrón de acumulación.}

La evolución del endeudamiento de la empresa Ferrocarriles Argentinos durante el período bajo estudio merece un capítulo aparte, dada su funcionalidad en la instauración de lo que sería un nuevo patrón de acumulación de capital en Argentina. Primeramente, cabe mencionar que el desempeño de FA en este aspecto no estuvo exento de los principales rasgos que caracterizaron la performance de la mayor parte de empresas públicas bajo el período dictatorial. En efecto, tal como se ha demostrado en otros trabajos (Iramain, 2015 y 2016), las firmas estatales en general y Ferrocarriles Argentinos en particular, se vieron expuestas a un intenso proceso de endeudamiento interno y externo, que, en líneas generales, no tuvo como correlato un incremento en los niveles de inversión real fija. Muy por el contrario, el grueso de dicho endeudamiento, en especial el nominado en moneda extranjera, resultó ser funcional al establecimiento de un nuevo régimen de acumulación de capital basado en la especulación financiera, la deuda externa y la fuga de capitales.

La situación de las firmas estatales fiscalizadas por la Sindicatura General de Empresas Públicas (SIGEP), entre las cuales se contaba Ferrocarriles Argentinos, experimentó un viraje muy significativo a partir del golpe de Estado de marzo de 1976 en materia de financiamiento. Si bien, históricamente, el ahorro de las empresas públicas había cubierto una baja proporción de sus inversiones, con la puesta en marcha de la política económica de la dictadura se cambió el criterio de cubrir los déficits operativos de las empresas públicas a través de los ATN. En esa línea, se instó a que dichas firmas obtuvieran un financiamiento a partir de recursos propios o mediante la recurrencia al mercado financiero local e internacional a fin de reducir su déficit presupuestario. En este marco, tal como se podrá observar en la Tabla 2, la empresa FA se vio sometida a un proceso de fuerte endeudamiento.

Cabe señalar que, por un lado, el endeudamiento interno del sector público, incluidas las empresas estatales de la envergadura de FA, coadyuvó a presionar al alza la tasa de interés interna a los efectos de generar un diferencial entre dicha tasa y la tasa de interés vigente en el mercado financiero internacional, lo cual constituía una premisa fundamental para la instauración de la denominada "bicicleta financiera". Por otro lado, la toma de préstamos en divisas por parte de las empresas públicas, contribuyó a proveer los fondos indispensables para que, una vez consumados los beneficios financieros por parte del sector privado, se pudiera completar el ciclo con la fuga de capitales. Todo ello se corrobora al analizar la evolución de la deuda externa pública y privada de la Argentina a lo largo del lapso 1976-1983.

En ese orden de ideas, cabe destacar que, en los primeros años de dicho período, el sector público fue el que motorizó el proceso de endeudamiento externo. Así las cosas, de 1976 a 1978, la deuda externa pública pasó de un monto inicial de 6.648 millones de dólares a una cifra de 9.453 millones de la misma moneda, llegando a representar cerca del 70\% de la deuda externa total del país ${ }^{6}$. Luego, de 1978 a 1980, la dinámica del endeudamiento externo estuvo liderada por el sector privado (en 1978 la deuda externa privada representaba casi el 31\% de la deuda externa total, mientras que tan sólo un año más tarde la proporción se había elevado al 48\%). Posteriormente, de 1980 a 1983, es nuevamente el sector público el que comanda las acciones en materia de toma de créditos en el exterior. La contracara de ese aumento de las obligaciones en moneda “fuerte” estuvo dada por la especulación financiera y la salida de capitales al exterior. ${ }^{7}$

En esa línea, la empresa de ferrocarriles también se vio sometida a tomar deuda tanto en el mercado 
financiero local como en el internacional. Ello se constata (Tabla 2) en el significativo incremento de las obligaciones en pesos y en moneda extranjera, entre los años 1978 y 1982, que como se observa en la tabla siguiente se incrementaron en casi un 330\% las primeras y en 262\%, las segundas.

Tabla 2: Evolución del endeudamiento interno* y externo** de Ferrocarriles Argentinos. 1978-1982.

\begin{tabular}{|c|c|c|c|c|c|c|}
\hline \multirow[b]{2}{*}{ Años } & \multicolumn{3}{|c|}{ Endeudamiento Interno $\left(^{( \pm t}\right)$} & \multicolumn{3}{|c|}{ Endeudamiento Externo } \\
\hline & $\begin{array}{c}\text { Miles. } \$ \text { de } \\
1960 \\
\end{array}$ & $\begin{array}{c}\text { Índice } \\
1978=100\end{array}$ & $\begin{array}{c}\text { Var. } \\
\text { interanual \% }\end{array}$ & Mill. U\$S & $\begin{array}{c}\text { Índice } \\
1978=100\end{array}$ & $\begin{array}{c}\text { Var. } \\
\text { interanual \% }\end{array}$ \\
\hline 1978 & 16.020 & 100 & & 193 & 100 & \\
\hline 1979 & 50.664 & 316.3 & 216.3 & 257 & 133.2 & 33.2 \\
\hline 1980 & 61.934 & 386.6 & 22,2 & 440 & 228 & 71,2 \\
\hline 1981 & 69.270 & 432,4 & 11.8 & 683 & 353.9 & 55.2 \\
\hline 1982 & 68.743 & 429.1 & $-0,8$ & 698 & 361.7 & 2.2 \\
\hline $\begin{array}{c}\text { Var.\% } \\
1982-1978\end{array}$ & \multicolumn{3}{|c|}{329,1} & \multicolumn{3}{|c|}{261,7} \\
\hline
\end{tabular}

* Saldos de deuda con instituciones financieras (excluida línea especial del Banco Nacional de Desarrollo), a fin de cada período, en el mercado interno, de acuerdo con la Resolución del Ministerio de Economía No 170/80.

** Saldo de endeudamiento en moneda extranjera al 31 de diciembre de cada año. *** En base al Índice de Precios Mayoristas Nacionales no Agropecuarios

Fuente: Elaboración propia en base a datos de la SIGEP (1984: 31-32).

Replicando lo sucedido a nivel global del sector público argentino, el correlato de ese aumento en las obligaciones internas y externas de Ferrocarriles Argentinos, no se tradujo, tal como se mencionó más arriba, en un incremento sustancial en los montos de inversión. Si bien es cierto que los niveles de inversión de 1983 eran bastante más elevados que los del comienzo de la dictadura en 1976, no obstante, tal como lo demuestra el siguiente cuadro (Tabla 3), la inversión real fija cayó poco más de un 1\% entre 1974 y 1983. Asimismo, a lo largo del período bajo análisis los importes de inversión fueron, a excepción de 1980, sistemáticamente más reducidos que los del año base. Incluso, en 1981 (un de los años de mayor incremento de la deuda externa de la empresa) no se verificó una suba en los niveles de inversión; sino que, por el contrario, los guarismos de dicho año fueron un 24\% menores que los de 1980. 
Tabla 3: Evolución de la Inversión Real Fija de Ferrocarriles Argentinos, 1974-1983 (en millones de pesos de 1960*, índice base 1974=100 y porcentajes)

\begin{tabular}{|c|c|c|c|}
\hline \multirow{2}{*}{ Años } & \multicolumn{3}{|c|}{ Ferrocarriles Argentinos } \\
\cline { 2 - 4 } & Mill. \$de 1960 & Índice base 1974=100 & Var. interanual \% \\
\hline 1974 & 65,9 & 100 & \\
\hline 1975 & 24,8 & 37,6 & $-62,4$ \\
\hline 1976 & 50,4 & 76,5 & 103,2 \\
\hline 1977 & 37,4 & 56,8 & $-25,8$ \\
\hline 1978 & 50,5 & 76,6 & 35 \\
\hline 1979 & 56 & 85 & 10,9 \\
\hline 1980 & 66,8 & 101,4 & 19,3 \\
\hline 1981 & 50,8 & 77,1 & -24 \\
\hline 1982 & 55,7 & 84,5 & 9,6 \\
\hline 1983 & 65 & 98,6 & 16,7 \\
\hline Var.\% 1983-1974 & & $\mathbf{- 1 , 4}$ & \\
\hline \hline
\end{tabular}

* En base al Índice de Precios Mayoristas Nacionales no Agropecuarios Fuente: Elaboración propia en base a datos de la SIGEP (1984: 24-25).

Los datos presentados resultan elocuentes en cuanto a la funcionalidad que tuvo el endeudamiento del sector público en general y de las empresas estatales en particular, para la instauración de un nuevo régimen de acumulación de capital basado en la valorización financiera y la internacionalización del excedente económico por parte del capital concentrado interno (los grandes grupos económicos locales y algunos conglomerados extranjeros de larga data en el país).

\section{El disciplinamiento de la clase trabajadora.}

En ese contexto de crecimiento del endeudamiento externo e interno, de caída de la inversión y, en especial, del desmantelamiento de la red ferroviaria y el cierre de talleres, es que cabe inscribir la política de reducción de la dotación de trabajadores de Ferrocarriles Argentinos. Empero, como se viene sosteniendo, dicha política, a su vez, se encuadró en una estrategia más amplia de disciplinamiento de los sectores populares en general y de la clase trabajadora en particular.

En efecto, tal como se ha indicado, uno de los propósitos centrales del autodenominado Proceso de Reorganización Nacional, fue la desarticulación, desmovilización y disciplinamiento de la clase obrera (Quiroga, 2004:65), en el marco de lo que algunos autores han señalado como una verdadera revancha oligárquica (Basualdo, 2010:117) o revancha clasista (Basualdo, 2013:90) por parte de los sectores dominantes representados, entre otras instancias, por el elenco gubernamental de la última dictadura cívicomilitar. Si bien la literatura especializada ha indagado los efectos de dicha revancha sobre los trabajadores de la industria manufacturera, en especial los del sector privado, se ha estudiado relativamente poco las consecuencias que la política económica de la dictadura tuvo para con los trabajadores del sector público en general y de las empresas estatales en particular.

En ese sentido, el personal de Ferrocarriles Argentinos no estuvo exento de esa revancha clasista y se vio expuesto a la estrategia de achicamiento de la empresa, cuyas principales variables de ajuste y 
racionalización fueron, precisamente, los salarios y los niveles de ocupación de los trabajadores.

Así las cosas, lo primero que cabe destacar es que la firma ferroviaria se vio sometida, al igual que otras empresas y reparticiones públicas, a un severo proceso de recorte de sus planteles laborales, en consonancia con el mentado principio de subsidiariedad estatal y la política de privatización periférica (Iramain, 2013, 2015 y 2016). En efecto, tal como se ha mencionado al comienzo de este trabajo, se puede observar una notable caída de la dotación de trabajadores de la empresa, que fue del orden del $27 \%$ en el período 19741983; ya que la cantidad de trabajadores pasó de 141.016 en 1974 a 103.102 al finalizar el ciclo de la dictadura. Empero, si se toma como punto de comparación el año 1976 con respecto a 1981, la caída se torna aún más pronunciada, dado que ronda poco más del 38\%. Esto muestra a las claras la tendencia descendente en materia de racionalización y reducción de personal encarada por la gestión de Martínez de Hoz. Recién en los dos últimos años de la experiencia procesista tendría lugar una leve recuperación de la plantilla laboral de la empresa ferroviaria.

Este proceso de reducción se dio en el marco de un gran cercenamiento de numerosas conquistas sociales para la clase obrera, como resultado de la aplicación del terrorismo de Estado, la política económica regresiva y los cambios en la legislación laboral con un sesgo contrario a los intereses de los trabajadores.

Entre los principales modificaciones en materia de normativa laboral cabe destacar que, además de las diversas leyes y decretos sancionados durante la dictadura que afectaban al conjunto de la clase trabajadora, en el caso particular de Ferrocarriles Argentinos se dictó una norma específica, la Ley 21.580 del 26 de mayo de 1977, que estableció un régimen especial de prescindibilidad para el personal declarado en disponibilidad. La misma supuso, entre otras cuestiones, la disminución de empleados como resultado de "las medidas sobre la clausura o levantamiento de líneas, ramales, estaciones y talleres y la supresión o reducción de servicios, emergentes de los programas de ordenamiento ferroviario" (Anales de Legislación Argentina, 1977:2461). La aplicación de dicha ley, en clara concordancia con la puesta en marcha del principio de subsidiariedad del Estado y el programa de privatización periférica encarados por la gestión de Martínez de Hoz, implicó la racionalización y eliminación de todos los componentes del sistema ferroviario considerados por las autoridades como "altamente deficitarios [ ...] y sin posibilidades de recuperación en un futuro previsible" (Anales de Legislación Argentina, 1977:2462).

De hecho, al amparo de los regímenes de prescindibilidad se llevó a cabo en 1978 el despido de 7.526 trabajadores en el ámbito de Ferrocarriles Argentinos; mientras que en 1979 todavía se registraban, bajo esa modalidad, la expulsión 1.655 agentes ferroviarios (SIGEP, 1980). Justamente, la empresa ferroviaria fue una de las más castigadas por la política de racionalización y “modernización” del aparato estatal propiciada por Martínez de Hoz. El menoscabo sufrido en la cantidad de trabajadores sobrepasó en mucho a lo experimentado por el resto de las firmas estatales. Asimismo, otro de los factores que suscitaron un significativo declive en la cantidad de personal ferroviario fue la aplicación de cesantías y sumarios, la cual trajo aparejada la expulsión 1.116 agentes en 1979 (SIGEP, 1980).

Ahora bien, lo que marca de manera nítida el componente de revancha clasista de la estrategia de disciplinamiento social encarada por la dictadura y de la consecuente política laboral en el ámbito de Ferrocarriles Argentinos, es que la referida caída en la dotación de recursos humanos no se distribuyó de manera homogénea entre las distintas categorías del personal.

Si bien la categoría que más descendió en el período 1974-1983, en términos relativos, fue la de empleados administrativos, la cual cayó más de un 43\% (pasó de 9.472 agentes en 1974 a 5.370 en 1983), algunas de las categorías más afectadas a lo largo del período bajo análisis fueron las que agrupaban a los trabajadores de menores niveles de calificación. Así, los empleados de mayordomía y maestranza cayeron un 37\% y los de atención de trenes y estaciones un 35\%, como consecuencia del cierre de muchas de ellas. Personal 
calificado como los conductores de locomotoras también sufrieron una disminución importante, producto de la menor cantidad de servicios, mermando un 34\% en igual período. Le siguieron en importancia los obreros, que pasaron de 56.095 en 1974 a 41.634 en 1983, alcanzado su pico más bajo en 1980 (36.611).

En ese contexto y en contraposición con el sesgo antiobrero de la política laboral aplicada al ámbito ferroviario, el personal directivo de la firma experimentó un aumento cercano al 30\% para el mismo período, dado que se pasó de un total de 7.993 agentes a otro de 10.365. Lo cual se condice con la retórica gubernamental (en particular la del gabinete económico liderado por Martínez de Hoz) de "eficientizar” y “modernizar” la gestión del Estado y las empresas públicas, mediante la incorporación de personal jerárquico afín a los principios rectores del Proceso de Reorganización Nacional.

Figura 3. Evolución del personal de Ferrocarriles Argentinos según calificación de la ocupación (en cantidades)

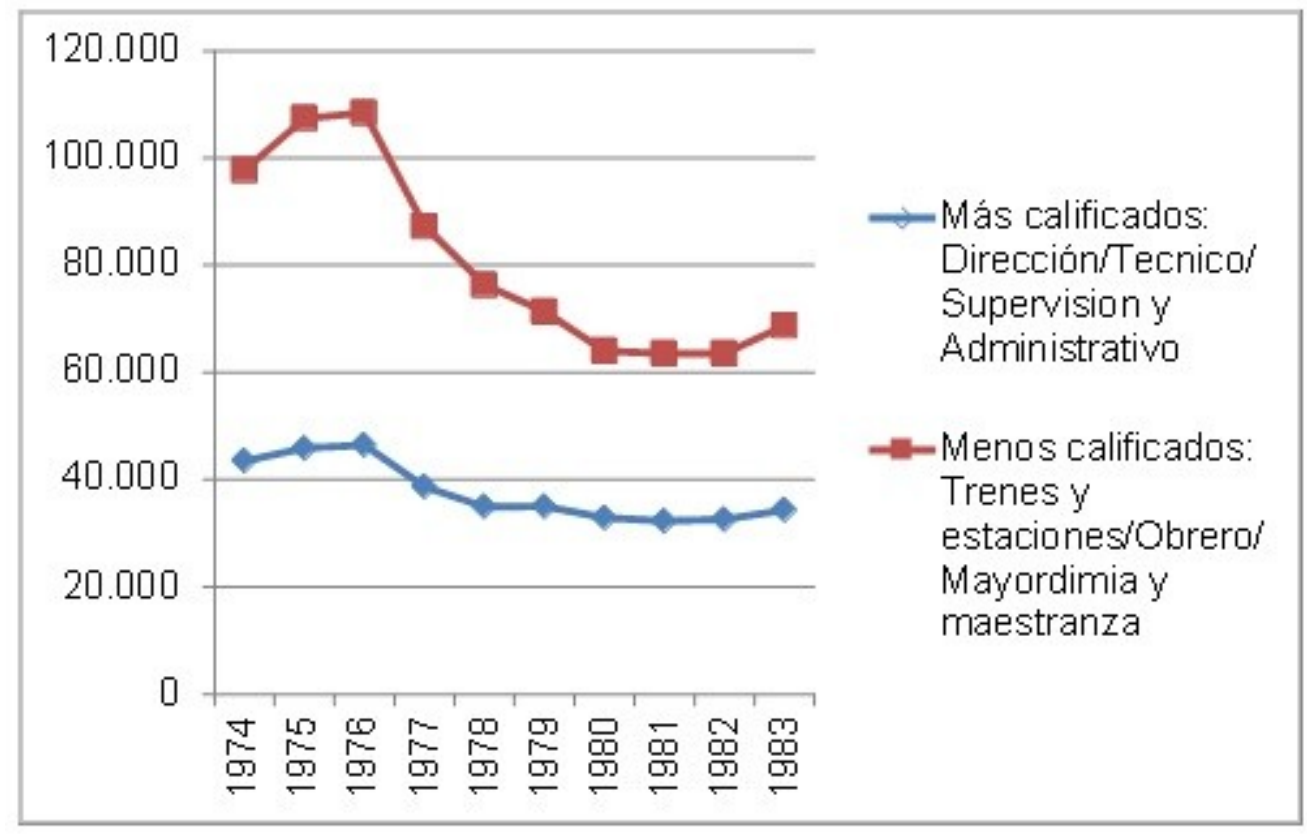

Fuente: Elaboración propia con base a datos de Ferrocarriles Argentinos (1976:3-4);

Ferrocarriles Argentinos (1981:4-5); Ferrocarriles Argentinos (1985:5-6).

Como se observa en el gráfico precedente (Figura 3), la caída experimentada entre los dos grupos construidos con base a la calificación de la tarea requerida, adquirió distinta intensidad. Mientras en conjunto el grupo de los más calificados (personal técnico, de dirección, de supervisión y administrativo) disminuyó un $21 \%$ en el período 1974-1983, el grupo menos calificado (personal de trenes y estaciones, obreros, mayordomía y maestranza) lo hizo en un 30\%, es decir, casi 10 puntos porcentuales más que el grupo anterior.

Otra herramienta de disciplinamiento hacia la clase trabajadora que se sumó a los despidos, cesantías y persecución en espacios de trabajo, fue la agudización de los controles de ausentismo. En efecto, según datos de SIGEP (1985) la tasa de ausentismo total ${ }^{8}$ en el ámbito de la empresa FA evolucionó de modo análogo al resto de las firmas y reparticiones públicas. Si se toma como pauta de comparación el período 1975-1983, es dable observar que el nivel ausentismo de 1983 eran un 26\% más bajo que el correspondiente al año 1975. De hecho, el ausentismo en la empresa ferroviaria descendió de manera sistemática desde 1976 hasta 1982 inclusive, sólo repuntando parcialmente en el ocaso del Proceso.

Otro de los componentes centrales de la revancha clasista emprendida por el Proceso fue el establecimiento de una distribución regresiva del ingreso a nivel de la economía en su conjunto, así como también, de modo 
más específico, en el ámbito de las empresas y organismos públicos. En efecto, la drástica caída del salario real decretada por el gobierno dictatorial ni bien usurpó el poder del aparato del Estado, fue una de las piezas clave de un engranaje más amplio destinado a disciplinar y reforzar el lugar de subordinación de la clase trabajadora en el marco del intento de refundar el capitalismo argentino sobre nuevas bases que llevó a cabo la coalición golpista a partir de marzo de 1976. En ese escenario y en consonancia con lo acaecido en el resto de las empresas públicas, es dable constatar que, más allá de las fuertes variaciones interanuales, la evolución de más largo aliento de los salarios reales de Ferrocarriles Argentinos, evidenció una pérdida de poder adquisitivo, entre 1974 y 1983, del orden del 5\% (Tabla 4).

De hecho, al igual que lo acontecido para el conjunto de la economía argentina, los trabajadores ferroviarios sufrieron una merma en sus remuneraciones desde el comienzo de la gestión de Martínez de Hoz. Tal es así, que ya en el primer año de la administración procesista los salarios de la firma ferrocarrilera cayeron, en comparación con los guarismos de 1975, un 24\%. Luego, en 1977 se registraría una nueva caída adicional de los salarios del 4\% interanual. A partir de allí, se asistiría a una recuperación de los ingresos de los trabajadores del sector durante el lapso 1978-1980, incluso evidenciando en algunos momentos niveles salariales superiores a los del año 1974 (por ejemplo, los salarios de 1980 eran casi 17\% más elevados que los de 1974). Empero, una vez desatada la crisis económica que signó la última etapa de la gestión liberalcorporativa de Martínez de Hoz y se extendió hasta el final de la dictadura, las remuneraciones ferroviarias padecerían en 1981 y 1982 un nuevo descenso, ubicándose, respectivamente un 7 y un 28\% por debajo del año base 1974. Luego, en 1983, los salarios de Ferrocarriles Argentinos experimentarían una parcial recuperación que, no obstante, no lograría revertir el severo deterioro del poder adquisitivo propiciado, sobre todo, en 1982.

\section{Tabla 4: Evolución del salario real bruto medio* de Ferrocarriles Argentinos, 1974-1983 (en índice base 1974=100)}

\begin{tabular}{|c|c|c|}
\hline Año & Salario real bruto medio & Salario real variación interanual \% \\
\hline 1974 & 100 & \\
\hline 1975 & 109.5 & 95 \\
\hline 1976 & 83,5 & $-23,7$ \\
\hline 1977 & 80,2 & -4 \\
\hline 1978 & 80,3 & 01 \\
\hline 1979 & 102,5 & 27.8 \\
\hline 1980 & 116,8 & 15.9 \\
\hline 1981 & 93,5 & -19.9 \\
\hline 1982 & 71,9 & $-23,1$ \\
\hline 1983 & 95.2 & 32.3 \\
\hline Var. \% & & \\
\hline $1983-1974$ & & $-4,8$ \\
\hline
\end{tabular}

*Nota: El salario real bruto medio surge del total de gastos en remuneraciones del personal en millones de pesos de 1970, deflactado sobre la base del Índice de Precios al Consumidor y dividido por la dotación de trabajadores al cierre de cada año.

Fuente: Elaboración propia en base a datos de la SIGEP (1984:14-19), FIDE (1984), Coyuntura y Desarrollo. Anexo Estadístico XVII, p. 5. 
En concomitancia con la reducción de la dotación de trabajadores y el decremento de los salarios reales, se asistió a un significativo aumento de la productividad de la mano de obra en la empresa de ferrocarriles. En ese orden de ideas, la tabla 5 resulta más que elocuente de la magnitud del incremento del producto por ocupado en la firma analizada, ya que se observa, pese a una caída circunstancial en el año 1981, una tendencia alcista a lo largo de todo el período 1974-1983. De hecho, la productividad de la fuerza de trabajo era al finalizar la dictadura en 1983 un 33\% más elevada que la registrada en el año base 1974. Es más, si se mide la evolución del producto por ocupado de Ferrocarriles Argentinos en el año 1983 con respecto al de 1976, se constata que aquél era casi 44 puntos porcentuales más elevado que los niveles registrados al comenzar el "Proceso".

Tabla 5: Evolución del producto por ocupado de Ferrocarriles Argentinos, 1974-1983 (índice base 1974=100 y porcentajes)

\begin{tabular}{|c|c|c|}
\hline \multirow{2}{*}{ Años } & \multicolumn{2}{|c|}{ Ferrocarriles Argentinos } \\
\cline { 2 - 3 } & $\begin{array}{c}\text { Índice base } \\
1974=100\end{array}$ & Variación \% \\
\hline 1974 & 100 & \\
\hline 1975 & 90.2 & -9.8 \\
\hline 1976 & 89.5 & -0.9 \\
\hline 1977 & 100.3 & 12.1 \\
\hline 1978 & 107.1 & 6.7 \\
\hline 1979 & 116.5 & 8.8 \\
\hline 1980 & 121.9 & 4,6 \\
\hline 1981 & 109 & -10.6 \\
\hline 1982 & 119.7 & 9.8 \\
\hline 1983 & 133 & 11.2 \\
\hline Var. $\mathbf{1 9 8 3}-$ & & $\mathbf{3 3}$ \\
\hline $\mathbf{1 9 7 4}$ & & \\
\hline
\end{tabular}

Fuente: Elaboración propia en base a datos de la SIGEP (1984: 9 y 18-19).

\section{Reflexiones Finales}

La política aplicada por la última dictadura en el ámbito de los ferrocarriles, estuvo en consonancia con el más amplio proyecto político y económico de carácter refundacional del capitalismo argentino que encaró el autodenominado Proceso de Reorganización Nacional. En efecto, si bien las tentativas de achicamiento y racionalización de los ferrocarriles databan de mucho tiempo antes, en particular, de la administración presidencial de Arturo Frondizi (1958-1962) y de los comienzos del gobierno de facto del general Onganía (1966-1970), lo cierto es que dichas tentativas no se habían inscripto bajo una lógica de una drástica reestructuración general de la economía y la sociedad argentinas como la llevada a cabo por la gestión procesista. En ese sentido, si bien cabe reconocer intentos previos de control y resubordinación de los sectores populares en general y de la clase trabajadora en particular, tales como el Plan Conintes también durante el gobierno frondicista y la implantación de un Estado burocrático - autoritario como el propiciado por la llamada Revolución Argentina (1966-1973), ninguno de ellos tuvo la profundidad e intensidad que ostentó el disciplinamiento social y la revancha clasista emprendidos por el Proceso. 
Es en esa clave que se torna inteligible la evidencia empírica consignada en el presente trabajo, dado que la totalidad de los indicadores elaborados y analizados muestran a las claras la deliberada estrategia de agresión hacia el entramado ferroviario como parte esencial del cambio en el régimen de acumulación de capital implementado, en especial, durante la gestión económica de Martínez de Hoz (1976-1981).

En ese marco, no resulta llamativo el acentuado deterioro al que se vio sometida la empresa FA a lo largo del período bajo estudio. Ello se pudo reflejar, entre otros datos, en los menores niveles de actividad económica de la firma, en la caída de los ingresos por ventas y en el descenso en el ranking de las 200 mayores empresas de la Argentina. Empero, el desmantelamiento de la red ferroviaria fue más pronunciado y alcanzó niveles sin precedentes, si se toma en cuenta la reducción en la cantidad de km de líneas, en la merma en el tráfico de pasajeros, en el cierre de ramales, estaciones y talleres; así como en la concomitante desarticulación del parque de material rodante. Esto demuestra el lugar marginal que, en términos de una estrategia de desarrollo, se le asignaba a los ferrocarriles desde el elenco gubernamental del Proceso.

Asimismo, cabe destacar que dicho desmantelamiento, tal como lo ilustran los datos sobre la evolución de los gastos en contratistas realizados por FA, tuvo como correlato la ingente transferencia de ingresos hacia el sector privado. Si bien todavía faltan estudios que identifiquen con mayor claridad el perfil y desempeño de los actores privados beneficiarios de la política de privatización periférica en el ámbito de FA, los indicios disponibles apuntan a que los ganadores, al igual que otros sectores de actividad durante el mismo período histórico, fueron los grupos económicos locales y algunos conglomerados extranjeros que formaban el núcleo de la denominada "patria contratista". Esto último constituye una fructífera línea de indagación para futuros trabajos.

En consonancia, con ese incremento de los gastos en contratistas, también se verificó el sustancial aumento de los niveles de endeudamiento interno y externo de la empresa ferrocarrilera; lo cual, resultó ser una pieza de un engranaje funcional a la instauración de un nuevo patrón de acumulación que pivoteó sobre el endeudamiento externo (público y privado), la valorización financiera, la fuga de capitales y la ulterior estatización de los pasivos externos del capital concentrado interno.

Finalmente, cabe subrayar una vez más, que una de las condiciones de posibilidad de la implantación de ese nuevo régimen de acumulación de capital, fue la puesta en marcha de una profunda revancha clasista y un vasto mecanismo de disciplinamiento social sobre las clases subalternas, que reconoció como dos de sus principales instrumentos al terrorismo de Estado y a la política económica implementada por Martínez de Hoz. En ese contexto, los trabajadores de FA, tal como lo ejemplifican los datos aportados en este trabajo, no estuvieron exentos de ese avance del capital y sus aliados civiles y militares del gobierno sobre sus condiciones de vida. En ese sentido, la reducción de los niveles de ocupación (en especial de la mano de obra de menores niveles de calificación), la caída de los salarios reales (en un contexto signado por un régimen de alta inflación), el aumento de la productividad laboral (como un indicador proxy de la intensificación de la explotación de la fuerza de trabajo) y la disminución de las tasas de ausentismo configuraron un escenario de avasallamiento y cercenamiento de históricas conquistas sociales por parte de la clase obrera argentina en su conjunto y particularmente de los trabajadores ferroviarios.

\section{Notas}

1. Sobre la deliberada estrategia de agresión el tejido manufacturero véase Azpiazu y Schorr (2010). Acerca de la caracterización de la gestión económica de Martínez de Hoz como liberal -corporativa véase Pucciarelli (2004). 
2. En la acepción utilizada en este trabajo, el concepto de Estado empresario propone como eje la acción empresarial del Estado, sin reducirlo a las empresas públicas. Siguiendo a Regalsky y Rougier (2015: 16) se concibe como Estado empresario aquél con capacidades para impulsar o sostener no sólo las actividades empresariales propias sino también otras de naturaleza privada y en las que participa no siempre directamente en la fase inicial.

3. En millones de pesos de 1970. Deflactado por el Índice de precios mayoristas nacionales no agropecuarios.

4. Los distintos componentes analizados son: gastos en personal, gastos en materiales, gastos en combustibles y lubricantes, gastos en contratistas y gastos varios.

5. Si bien en 1976 se implementó un ajuste de precios del orden del 30\% en las tarifas de servicios públicos destinado a restablecer cierto equilibrio de precios en favor de las empresas públicas (Basualdo, 2010: 127), con los años, estos precios quedarían rezagados respecto a los de otros de la economía. Esto fue así porque como se ha mencionado, el control de precios formó parte de las medidas implementadas por el gobierno, con vistas a frenar el proceso inflacionario que azotaba a la Argentina.

6. Una parte no desdeñable de esos préstamos nominados en moneda extranjera fueron direccionados a la formación de una significativa reserva de divisas, la cual, en esos primeros años de la dictadura, creció cerca de 10.000 millones de dólares. Ese incremento de las reservas tenía, originalmente, como propósito esencial crear las condiciones propicias para la ulterior instrumentación del plan de estabilización de diciembre de 1978, basado en el enfoque monetario del balance de pagos. Cfr. Rapoport (2003: 811).

7. También es dable mencionar que parte del incremento de los pasivos externos del sector público estuvo destinado a la compra de material bélico por parte del Estado argentino, en el marco de los conflictos que éste mantenía con Chile por el Canal del Beagle y, al mismo tiempo, en la medida que se preparaba de manera subrepticia para el desembarco en las Islas Malvinas y el concomitante enfrentamiento con Gran Bretaña. Cfr. Rapoport (2003: 812).

8. Se parte de una dotación de personal o dotación física que es "todo aquel personal que en el período considerado se encuentra en relación de dependencia con la Empresa, aun cuando permanezca inactivo por alejamiento transitorio de sus tareas”. Este total de personal se multiplica por el total de días trabajados en el mes y se obtiene entonces el total mensual de “días-hombre”. El porcentaje total de ausentismo en cada mes, se obtiene relacionando el total de días-hombre correspondiente a las ausencias por todo concepto, con respecto al total de días-hombre de la dotación física: Total ausencias x 100/Dotación física.

\section{Bibliografía}

Acevedo, M., Basualdo, E. y Khavisse, M. (1991) ¿Quién es quién? Los dueños del poder económico (Argentina 1973-1987). Buenos Aires: Editora / 12 -Pensamiento Jurídico Editora.

Azpiazu, D. y Schorr, M. (2010) Hecho en Argentina. Industria y economía, 1976-2007. Buenos Aires: Siglo XXI.

Basualdo, E. (2010) Estudios de historia económica argentina. Desde mediados del siglo XX a la actualidad. Buenos Aires: FLACSO/Siglo XXI.

Basualdo, E. (2013) El legado dictatorial. El nuevo patrón de acumulación de capital, la desindustrialización y el ocaso de los trabajadores. En Verbitsky H. y Bohoslavsky J.P. (edit.), Cuentas pendientes. Los cómplices económicos de la dictadura (pp. 81-99). Buenos Aires: Siglo XXI. 
Canelo, P. (2004) La política contra la economía: los elencos militares frente al plan económico de Martínez de Hoz durante el Proceso de Reorganización Nacional (1976-1981). En Pucciarelli A. (coord.), Empresarios, tecnócratas y militares. La trama corporativa de la última dictadura (pp. 219-312). Buenos Aires: Siglo XXI.

Canelo, P. (2008) El proceso en su laberinto. La interna militar de Videla a Bignone, Buenos Aires: IDAESUNSAM/Prometeo.

Castellani, A. (2009) Estado, empresas y empresarios. La construcción de ámbitos privilegiados de acumulación entre 1966 y 1989. Buenos Aires: Prometeo Libros.

Dandan, Alejandra. (2011, febrero 16). El juicio por los obreros de Astarsa. Página 12. El país.

Ferreres, O. (Dir.) (2010) Dos siglos de economía argentina 1810-2004. Edición Bicentenario. Buenos Aires: Fundación Norte y Sur.

Gastiazoro, E. (1988). Ferrocarriles. Historia, actualidad y propuestas. Buenos Aires: Agora.

Iramain, Lucas. (2013) Política económica en la dictadura. La orientación y calidad de la intervención económica del Estado en el sector vial. La actuación de la Dirección Nacional de Vialidad (DNV) (Argentina, 1976-1981) [en línea] [consulta: agosto de 2014] $<$ http://www.idaes.edu.ar/sitio/publicaciones/DocIS 24 Iramain.pdf $>$

Iramain, Lucas (2015). La política laboral del 'Proceso' en torno a las empresas públicas. Los casos de ENTEL, Gas del Estado y Ferrocarriles Argentinos (1976-1983). [en línea] [consulta: mayo de 2016] http://www.unicen.edu.ar/iehs/files/04\%20Anuario\%20IEHS\%2029\&30.Iramain.pdf

Iramain, Lucas (2016). Privatización periférica, endeudamiento externo y disciplinamiento de la fuerza de trabajo. El desempeño de las empresas públicas del sector energético durante la última dictadura cívicomilitar argentina (1976-1983), En Rougier M. y Odisio J. (comp.), Estudios sobre planificación y desarrollo, vol. 1. (pp. 281-306). Carapachay: Lenguaje Claro Editora.

Martínez, J. P. (2007). 1977-2006: El ciclo de las reformas traumáticas. En Nueva historia del ferrocarril en Argentina. 150 años de política ferroviaria (pp.209-292). Buenos Aires: Lumiere.

Müller, A. (2012) Racionalización en el ferrocarril estatal argentino: ¿qué se logró? VI Congreso de Historia Ferroviaria. Vitoria, España.

Novaro, M. y Palermo, V. (2003) La dictadura militar 1976/1983. Buenos Aires: Paidós.

Pucciarelli, A. (2004) La patria contratista. El nuevo discurso liberal de la dictadura militar encubre una vieja práctica corporativa. En Pucciarelli A. (coord.), Empresarios, tecnócratas y militares. La trama corporativa de la última dictadura. (pp. 99-171). Buenos Aires: Siglo XXI.

Quiroga, H. (2004) El tiempo del "Proceso". Conflictos y coincidencias entre políticos y militares 19761983. Rosario: Editorial Fundación Ross/Homo Sapiens Ediciones.

Rapoport, M. (2003) Historia económica, política y social de la Argentina (1880-2000). Buenos Aires: Macchi.

Regalsky, A. y Rougier, M. (2015) Los derroteros del Estado empresario en la Argentina. Buenos Aires: Siglo XX/EDUNTREF.

Rougier, M. (2008) El estado y sus empresas en el desempeño económico argentino de la segunda mitad del siglo XX. Una revisión necesaria. IX Congreso Internacional de la Asociación Española de Historia Económica. Murcia, España. 
Schvarzer, J. (1986) La política económica de Martínez de Hoz. Buenos Aires: Hyspamérica.

Zlotnik, Claudio y Dellatorre, Raúl. (2000, diciembre 12) Los gobiernos pasan pero Kogan no se baja. Página 12.

\section{Fuentes}

Anales de Legislación Argentina (1977): Ley No 21.580, tomo XXXVII-C, Buenos Aires, Editorial La Ley, Biblioteca Legal del Ministerio de Economía y Finanzas Públicas de la Nación.

Ferrocarriles Argentinos (1976), Síntesis estadística de los Ferrocarriles en explotación, 1971-1975, Buenos Aires, Biblioteca del Ministerio de Economía y Finanzas Públicas de la Nación.

Ferrocarriles Argentinos (1981), Síntesis estadística de los Ferrocarriles en explotación, 1976-1980, Buenos Aires, Biblioteca del Ministerio de Economía y Finanzas Públicas de la Nación.

Ferrocarriles Argentinos (1985), Síntesis estadística de los Ferrocarriles en explotación, 1980-1984, Buenos Aires, Biblioteca del Ministerio de Economía y Finanzas Públicas de la Nación.

FIDE, revista Coyuntura y Desarrollo, varios números. Biblioteca del Ministerio de Economía y Finanzas Públicas de la Nación.

Ministerio de Economía de la Nación (1982); Memoria del Ministerio de Economía 1976-1981, tomo II, Biblioteca del Ministerio de Economía y Finanzas Públicas de la Nación.

SIGEP (1980): “Administración de los Recursos Humanos. Su relación con la eficiencia del Sector Público. El caso de las Empresas Públicas (SIGEP)”. Informe al Directorio No 05/80, Buenos Aires, Biblioteca del Ministerio de Economía y Finanzas Públicas de la Nación.

SIGEP (1984): Síntesis estadística anual de las empresas públicas, año 1983, Buenos Aires, Biblioteca del Ministerio de Economía y Finanzas Públicas de la Nación.

SIGEP (1985), Ausentismo en las Empresas Públicas. Período 1975-1984, Buenos Aires, Biblioteca del Ministerio de Economía y Finanzas Públicas de la Nación. 